\title{
Comparison of the Interleukin-1 $\beta$-Inducing Potency of Allergenic Spores from Higher Fungi (Basidiomycetes) in a Cryopreserved Human Whole Blood System
}

\author{
Félix E. Rivera-Mariani ${ }^{a, c}$ Kranthi Vysyaraju ${ }^{b}$ Jesse Negherbon ${ }^{a}$ \\ Estelle Levetin $^{d}$ W. Elliot Horner ${ }^{\mathrm{e}}$ Thomas Hartung $^{\mathrm{a}-\mathrm{c}}$ Patrick N. Breysse ${ }^{\mathrm{a}}$ \\ Departments of a Environmental Health Sciences and ${ }^{\mathrm{b}}$ Molecular Microbiology and Immunology, and ${ }^{\mathrm{c} C e n t e r}$ \\ for Alternatives to Animal Testing, Bloomberg School of Public Health, Johns Hopkins University, Baltimore, Md., \\ ${ }^{\mathrm{d}}$ Department of Biological Sciences, University of Tulsa, Tulsa, Okla., and e UL Environment Air Quality Services, \\ Marietta, Ga., USA
}

\section{Key Words}

Basidiospores · Human whole blood · Interleukin-1 $1 \beta$.

Proinflammatory potency

\begin{abstract}
Background: Spores from basidiomycete fungi (basidiospores) are highly prevalent in the atmosphere of urban and rural settings. Studies have confirmed their potential to affect human health as allergens. Less is known about their potential to serve as stimuli of the innate immune system and induce proinflammatory reactions. Methods: In this study, we evaluated the proinflammatory potential of spores from 11 allergenic basidiomycete species (gilled: Pleurotus ostreatus, Oudemansiella radicata, Armillaria tabescens, Coprinus micaceus, Pluteus cervinus, and Chlorophyllum molybdites, and nongilled: Pisolithus arhizus, Merulius tremellosus, Calvatia cyathiformis, Lycoperdon pyriforme, and Boletus bicolor) based on their potency to induce the release of the proinflammatory cytokine interleukin (IL)- $1 \beta$ in a cryopreserved human whole blood system. In addition, the roles of morphological features of the spores (surface area, shape, and pigmentation) were examined for their role in the IL-1 $\beta$ including potency of spores. Peripheral blood from healthy volunteers was collected, pooled, and cryopreserved. After
\end{abstract}

stimulating the cryopreserved pooled blood with $10^{6}$ to $10^{3}$ basidiospores $/ \mathrm{ml}$, the concentration of IL-1 $\beta$ in culture supernatants was determined with ELISA. Results: Basidiospores manifested concentration-dependent IL-1 $\beta$-inducing potency, which was more marked among basidiospores from gilled basidiomycetes. At higher concentrations of basidiospores, the IL-1 $\beta$-inducing potency could be differentiated in the cryopreserved human whole blood system. Morphological features did not correlate with the IL- $1 \beta$-inducing potency of the basidiospores, suggesting that nonmorphological properties modulate the IL-1 $\beta$-inducing potency. Conclusion: Our data provide evidence of the proinflammatory potential of basidiospores, and the utility of cryopreserved human whole blood as a human-based in vitro system to study the immune reactivity of allergenic basidiospores.

(c) 2013 S. Karger AG, Basel

\section{Introduction}

Fungal spores are an important biological component in the atmosphere of urban and rural settings worldwide [1-3]. The ecology of airborne fungal spores in the atmosphere of urban and rural settings is not limited to those

\section{KARGER}

E-Mail karger@karger.com

www.karger.com/iaa
(C) 2013 S. Karger AG, Basel

$1018-2438 / 13 / 1632-0154 \$ 38.00 / 0$ 
of mitosporic micromycetes (e.g. Cladosporium spp., Alternaria spp., Aspergillus spp., and Penicillium spp.), but also include those from the basidiomycota group (e.g. Coprinus spp. Pleurotus spp., and Chlorophyllum spp.) [1, 4-6]. In addition to contributing to the biological diversity, spores of basidiomycetes (basidiospores) are also sources of the organic component of airborne particulate matter that interacts with the human respiratory system $[2,7,8]$. More importantly, studies have documented the allergenic potential of basidiospores and their possible link with incidences of chronic proinflammatory respiratory diseases, such as asthma and allergic rhinitis [9-12]. Therefore, more information about the health effects of basidiospores following interaction with the human immune system is warranted.

The aerodynamic size of fungal spores varies between species, but many of them, including those of basidiomycetes, are small enough to penetrate deep into the respiratory tract and interact with cells of the immune system [13-16]. This interaction often leads to the activation of innate immune cells and subsequent release of proinflammatory mediators, such as the cytokine interleukin (IL)-1 $\beta$. Nevertheless, most studies that have evaluated the innate immune activation potential of fungi have focused on fungal pathogens (e.g. Candida spp., Aspergillus spp., and Cryptococcus spp.). Less is known about basidiospores. Given the potential of basidiospores to interact with cells of the immune system, the potential of basidiospores to activate the innate immune system should be evaluated.

Human whole blood provides a feasible system to evaluate immune function because cells of the immune system react in their natural environment (e.g. cell-to-cell and cell-to-serum component interactions), which is important for proper immune reactivity. This advantage of human whole blood was exploited to detect pyrogenic (proinflammatory) contamination of parenterals, and to evaluate proinflammatory potency of non-lipopolysaccharide (LPS) microbial compounds and the concentration-dependent proinflammatory potential of airborne particulate matter samples [17-22]. This assay has been internationally validated for pyrogenic testing of pharmaceuticals and medical devices [23, 24]. The modification of pooling and cryopreserving the blood allows for high-throughput examination of numerous samples, makes the cryopreserved blood an immediately accessible reagent, and overcomes the artifact of interindividual variability in immune reactivity [23-25]. Because responses of human whole blood have been comparable to that of alveolar macrophages, this assay may also enable the assessment of the potential of a sample to induce lung proinflammatory responses [23]. Human whole blood, therefore, can provide a tool to evaluate the proinflammatory potential of components of airborne particulate matter, such as fungal spores from basidiomycetes, which may pose a health risk to individuals suffering from respiratory diseases (e.g. asthma and allergies).

In this study, we determined the proinflammatory potency of spores from 11 species of fungi from the basidiomycota group with documented allergenic potential, based on the release of the proinflammatory cytokine IL$1 \beta$ from cells in cryopreserved human whole blood. Given that the morphology of spores is highly diverse throughout the fungus kingdom, we evaluated the role of morphological features, such as surface area, shape, and spore pigmentation, in the IL- $1 \beta$-inducing potency of the basidiospores.

\section{Methods}

All chemicals, reagents, and materials used throughout the experiments listed in this section were free of pyrogen.

\section{Basidiospores}

Fruiting bodies of basidiomycetes (table 1) were collected from a recreational area in Baltimore (Md., USA); others were collected and shipped from Tulsa (Okla., USA) and Atlanta (Ga., USA) by collaborators in this study. They were brought into the laboratory in clean paper bags. The stipe of the fruiting bodies was removed and the basidocarp placed overnight on depyrogenized aluminum foil to collect basidiospore deposits. The basidiospore deposits were aseptically transferred into microcentrifuge tubes (ThermoFisher Scientific, Waltham, Mass., USA) and stored in a desiccator until analyzed. Loopfuls of basidiospore deposits were transferred into microcentrifuge tubes containing $1 \mathrm{ml}$ of water. The concentration of basidiospores (spores/ml) for each species was determined with a hemocytometer, and dilutions $\left(1.0 \times 10^{6}, 10^{5}, 10^{4}\right.$, and $10^{3}$ spores $/ \mathrm{ml}$ ) were prepared for each species. These basidiospore dilutions were later tested in the cryopreserved human whole blood system.

\section{Collection and Cryopreservation of Human Whole Blood}

With prior approval of the Johns Hopkins School of Public Health Institutional Review Board, healthy volunteers were recruited from the Johns Hopkins School of Public Health staff and they orally consented to participate in the study. Blood $(30 \mathrm{ml})$ was collected by venipuncture into heparinized vacutainer tubes (Becton Dickinson, Franklin Lakes, N.J., USA). Incubations using fresh whole blood must be started within $4 \mathrm{~h}$ of blood sampling, as reactivity was significantly lower when challenged with pyrogens at later time points $[24,25]$. To mitigate this limitation, whole blood was collected from multiple donors, pooled, and cryopreserved as previously described with minor modifications [25]. Vacutainer tubes were placed in ice before pooling the blood into 50-ml Falcon $^{\circledR}$ tubes (Becton Dickinson). The blood was gently pooled into 
Table 1. Species of basidiomycetes tested and corresponding morphological measurements

\begin{tabular}{|c|c|c|c|c|c|}
\hline Basidiomycete species & $\begin{array}{l}\text { Macroscopical } \\
\text { description }\end{array}$ & $\begin{array}{l}\text { Surface area, } \\
\text { pixels }^{2}\end{array}$ & $\begin{array}{l}\text { Circularity }{ }^{\mathrm{a}} \\
\mathrm{R}\end{array}$ & Pigmentation $^{\mathrm{b}}$ & $\begin{array}{l}\text { LPS contamination, } \\
\text { ng } / 10^{6} \text { spores }\end{array}$ \\
\hline P. arhizus & puffball $^{\mathrm{c}}$ & 3,811 & 0.685 & 37,233 & 0.032 \\
\hline P. ostreatus & gilled mushroom ${ }^{\mathrm{d}}$ & 3,538 & 0.673 & 141,739 & 0.154 \\
\hline O. radicata & gilled mushroom & 3,859 & 0.801 & 116,635 & 0.161 \\
\hline A. tabescens & gilled mushroom & 3,382 & 0.653 & 96,399 & 0.049 \\
\hline M. tremellosus & polypore $\mathrm{e}^{\mathrm{e}}$ & 3,196 & 0.635 & 143,335 & 0.141 \\
\hline C. cyathiformis & puffball & 3,070 & 0.544 & 42,412 & $<$ LOD \\
\hline C. micaceus & gilled mushroom & 3,223 & 0.601 & 52,075 & 0.163 \\
\hline L. pyriforme & puffball & 3,108 & 0.576 & 92,790 & 0.032 \\
\hline P. cervinus & gilled mushroom & 3,398 & 0.646 & 97,402 & $<$ LOD \\
\hline C. molybdites & gilled mushroom & 3,398 & 0.646 & 90,258 & $<\mathrm{LOD}$ \\
\hline B. bicolor & polypore & 3,357 & 0.642 & 105,889 & $<\mathrm{LOD}$ \\
\hline
\end{tabular}

Italic numbers correspond to the highest and lowest values within each column.

${ }^{a}$ Circularity of a sphere, rectangle, and star-shaped object is $1.000,0.670$, and 0.086 , respectively. ${ }^{b}$ Pigmentation (as a measure of color-integrated density) of a black object and the background of the images is 0 and 184,563 , respectively. ${ }^{\mathrm{c}}$ Puffballs produce basidiospores in an internal fruiting body. ${ }^{\mathrm{d}}$ Gilled mushrooms have basidiospore-bearing gills. ${ }^{e}$ Polypores have basidiospore-bearing tubes in the fruiting body.

a 1-liter Nalgene ${ }^{\circledR}$ storage bottle (Thermo Scientific), and clinical grade dimethyl sulfoxide (DMSO; Gaylord Chemical, Slidell, La., USA) was added slowly into the pooled blood, with gentle mixing, until the concentration of DMSO reached $10 \%$ of the final volume. The pooled whole blood with DMSO was aliquoted into precooled $4.5-\mathrm{ml}$ cryovials. The cryovials were kept at $4^{\circ} \mathrm{C}$ for $20 \mathrm{~min}$, stored at $-20^{\circ} \mathrm{C}$ for an additional $20 \mathrm{~min}$, and were then placed in a Styrofoam box and stored at $-80^{\circ} \mathrm{C}$. The Styrofoam box was used to control the decrease in temperature of the cryovials once stored at $-80^{\circ} \mathrm{C}$. Quality control tests of the cryopreserved batches of blood were performed to make sure that it maintained its reactivity against a standard stimulus $(0.5 \mathrm{ng} / \mathrm{ml}$ of LPS from Escherichia coli O113:H10; Associates of Cape Cod, East Falmouth, Mass., USA), and displayed a consistent and minimal baseline reactivity (e.g. $\leq 5$ pg IL-1 $\beta / \mathrm{ml}$ ) to the culture medium (RPMI 1640; Invitrogen, Carlsbad, Calif., USA). The incubation protocol for the quality control tests included the positive control [180 $\mu$ l of RPMI, $40 \mu \mathrm{l}$ of thawed blood, and $20 \mu \mathrm{l}$ of LPS from E. coli O113:H13 (0.5 ng/ $\mathrm{ml})$ ], and the negative control $(200 \mu \mathrm{l}$ of RPMI and $40 \mu \mathrm{l}$ of thawed blood). ELISA of the supernatant for IL- $1 \beta$ was performed as described below.

\section{Stimulation of Cryopreserved Human Whole Blood}

The stimulation of the thawed cryopreserved human whole blood was performed as previously described with minor modifications. Basidiospore suspensions (final concentrations of $1.0 \times$ $10^{6}, 10^{5}, 10^{4}$, and $10^{3}$ spores $/ \mathrm{ml}$ ) were incubated in triplicate in 180 $\mu \mathrm{l}$ of RPMI 1640 in the presence of 25 international units (IU) of the polycationic antibiotic polymyxin B sulfate (Xgen Pharmaceuticals, Big Flats, N.Y., USA) for $1 \mathrm{~h}$ at $37^{\circ} \mathrm{C}$. This compound has high affinity to negatively charged phosphate groups, such as those present in the LPS from Gram-negative bacteria. Preincubation with 25 IU of polymyxin B sulfate was performed to inhibit any contamination of the basidiospores with LPS, which is a strong stimulus of innate immune cells. The concentration of polymyxin B sulfate used was determined in a preliminary study, in which 25 IU were found to be effective in blocking the IL- $1 \beta$ response of 0.5 ng of LPS of E. coli O113:H10 and at the same time was not toxic to the cells in the cryopreserved blood (data not shown). The level of LPS contamination was determined with the kinetic chromogenic Limulus amoebocyte lysate assay Pyrochrome ${ }^{\circledR}$ (Associates of Cape Code), following the manufacturer's instructions, prior to performing the whole blood assay (table 1). After preincubation with polymyxin $\mathrm{B}$ sulfate, vials of cryopreserved blood were thawed for $15 \mathrm{~min}$ at $37^{\circ} \mathrm{C}$ and $5 \% \mathrm{CO}_{2}$. The thawed blood was then stimulated with the basidiospores suspensions or controls within 15 min to avoid any toxic effects that the DMSO may have on the blood immune cells [25]. Forty microliters of thawed blood were transferred into the wells containing the basidiospore suspension, the plate gently tapped for $30 \mathrm{~s}$, and incubated at $37^{\circ} \mathrm{C}$ and $5 \% \mathrm{CO}_{2}$ for $18 \mathrm{~h}$. After incubation, the culture supernatants were collected and stored at $-80^{\circ} \mathrm{C}$ until ELISA was performed with capture and biotinylated-detection antibody pairs for the proinflammatory cytokine IL-1 $\beta$ (R\&D Systems, Minneapolis, Minn., USA). Serial dilutions of LPS $(0.5,0.25$, and $0.1 \mathrm{ng} / \mathrm{ml})$ from $E$. coli O113:H10 and RPMI 1640 alone were included as positive and negative controls, respectively; fig. 2a). Reagent controls, for water and polymyxin $B$ sulfate, were performed and yielded no response (data not shown).

\section{Microscopy and Image Analysis of Spores}

Microscopic slides of each species of basidiospores were prepared by placing a loopful of basidiospore dilution on a clean microscope slide and allowing it to air-dry overnight. Slides were examined at a magnification of $\times 1,000$ with a Nikon Eclipse E800 (Nikon, Melville, N.Y., USA) microscope connected to a SPOT RT3 (Diagnostic Instruments, Sterling Heights, Mich., USA) camera synchronized to a computer. Two images/slide were captured with the software SPOT Advanced (Diagnostic Instruments) and 


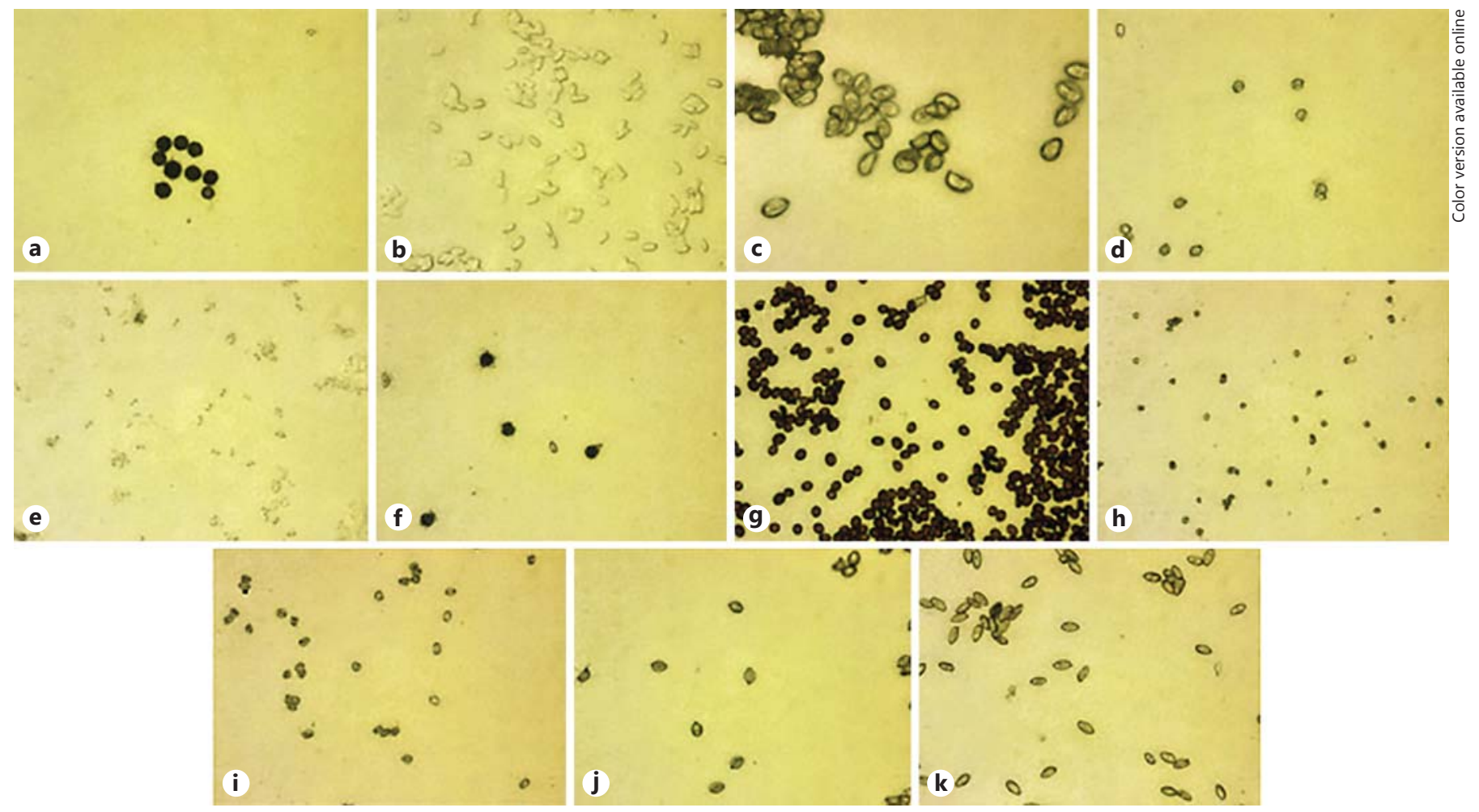

Fig. 1. Images of basidiospores $(\times 1,000)$. a $P$. arhizus. b $P$. ostreatus. c O. radicata. d A. tabescens. e M. tremellosus. f C. cyathiformis. $\mathbf{g}$ C. micaceus. $\mathbf{h}$ L. pyriforme. $\mathbf{i}$ P. cervinus. $\mathbf{j}$ C. molybdites. $\mathbf{k}$ B. bicolor.

analyzed with the image analysis software ImageJ (National Institutes of Health, Bethesda, Md., USA) for surface area (pixel²), spore pigmentation (integrated density of the basidiospore color), and shape (measure of circumference). Measurements of the above morphological features were performed on 10 spores/slide.

Each image was color segmented to isolate the particle of interest (spores) from the background. After segmentation, measurement options for surface area, integrated density, and circularity were selected. The software automatically calculated the selected measurements, and the results were exported into an Excel ${ }^{\mathrm{TM}}$ file. As reference, the circularity ranges were from 0 to 1 : a sphere, rectangle, and star-shape object have circularities of $1,0.6$, and 0.08 , respectively [26]. For integrated density, a completely black object has an integrated density of 0 and the background of the image of the basidiospores had an integrated density of 184,563 . Therefore, the more hyaline or brightly colored a spore, the higher the number and closer to the integrated density of the background.

\section{Statistical Analysis}

Statistical analysis was performed with Minitab 16.2.2 (Minitab Inc., State College, Pa., USA). The morphological and cytokine data did not show a normal distribution, as determined by an Anderson-Darling normality test. A two-sample Wilcoxon rank sum test was performed to determine significant differences between the highest IL- $1 \beta$-inducing potency of basidiospores and LPS concentrations of 0.5 and $0.25 \mathrm{ng} / \mathrm{ml}$. Levene's test of equal variance was performed to determine the concentration of basidiospores/ $\mathrm{ml}$ that induced the highest variability in the IL- $1 \beta$-inducing potency. The concentration of basidiospores with the highest variability in IL-1 $\beta$-inducing potency (determined by Levene's test of equal variance) was used to test for any correlation with the morphological features of the basidiospores (surface area, circularity, and color integrated density). Significance was set at $\mathrm{p}<0.05$.

\section{Results}

\section{Basidiospores Induced Concentration- and Species-Dependent IL-1 $\beta$ Responses}

To compare the IL- $1 \beta$-inducing potency of spores from the 11 basidiomycete species (table 1; fig. 1), cryopreserved human whole blood was stimulated with different concentrations $\left(10^{6}-10^{3}\right)$ of basidiospores and the concentration of IL-1 $\beta$ in the culture supernatant was measured with ELISA. Human whole blood was also incubated with $0.5,0.25$, and $0.1 \mathrm{ng} / \mathrm{ml}$ of LPS. Any LPS contamination of the basidiospores was blocked with 25 IU of polymyxin B sulfate.

As expected, stimulation of human whole blood with the three concentrations of LPS (fig. 2a) induced a con- 


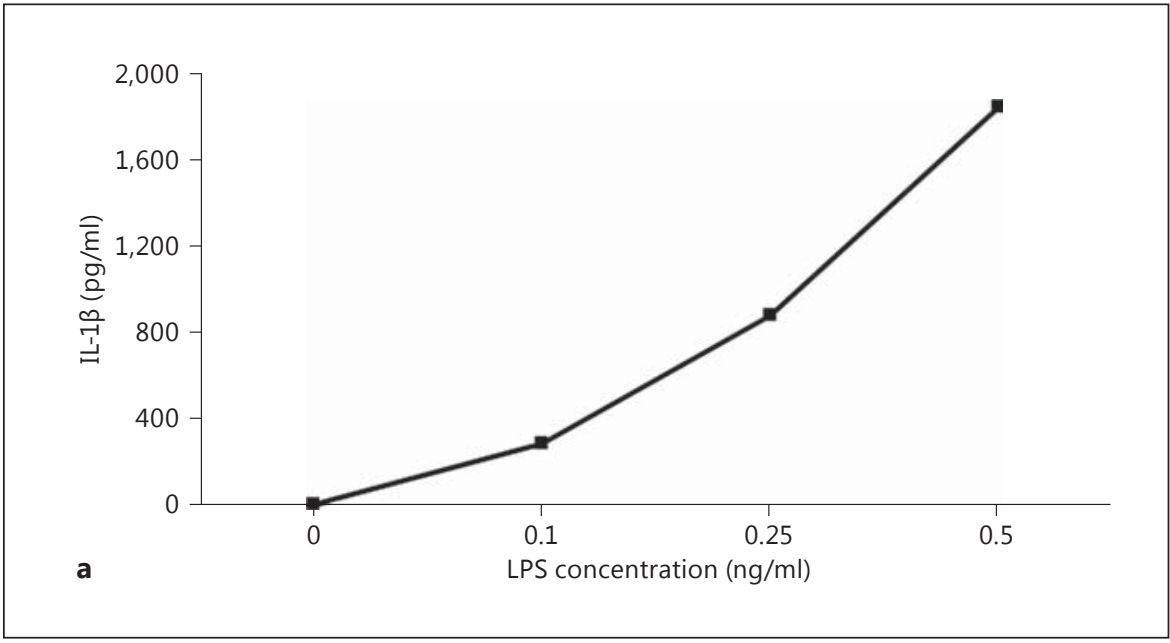

Fig. 2. Concentration-dependent responses of LPS and basidiospores in cryopreserved human whole blood. Cryopreserved human whole blood was stimulated with LPS (a), and spores from gilled (b), and puffball and polypore basidiomycetes (c), and concentrations of the proinflammatory cytokine IL- $1 \beta$ in culture supernatants were determined with ELISA. Long-dash and dash lines represent the IL- $1 \beta$-inducing potency of 0.5 and $0.25 \mathrm{ng} / \mathrm{ml}$, respectively. Representative data from three independent experiments are shown. ${ }^{* *} \mathrm{p}<0.05$ vs. $0.5 / 0.25 \mathrm{ng} / \mathrm{ml}$ of LPS; ${ }^{*} \mathrm{p}<0.05$ vs. $0.25 \mathrm{ng} /$ $\mathrm{ml}$ of LPS.
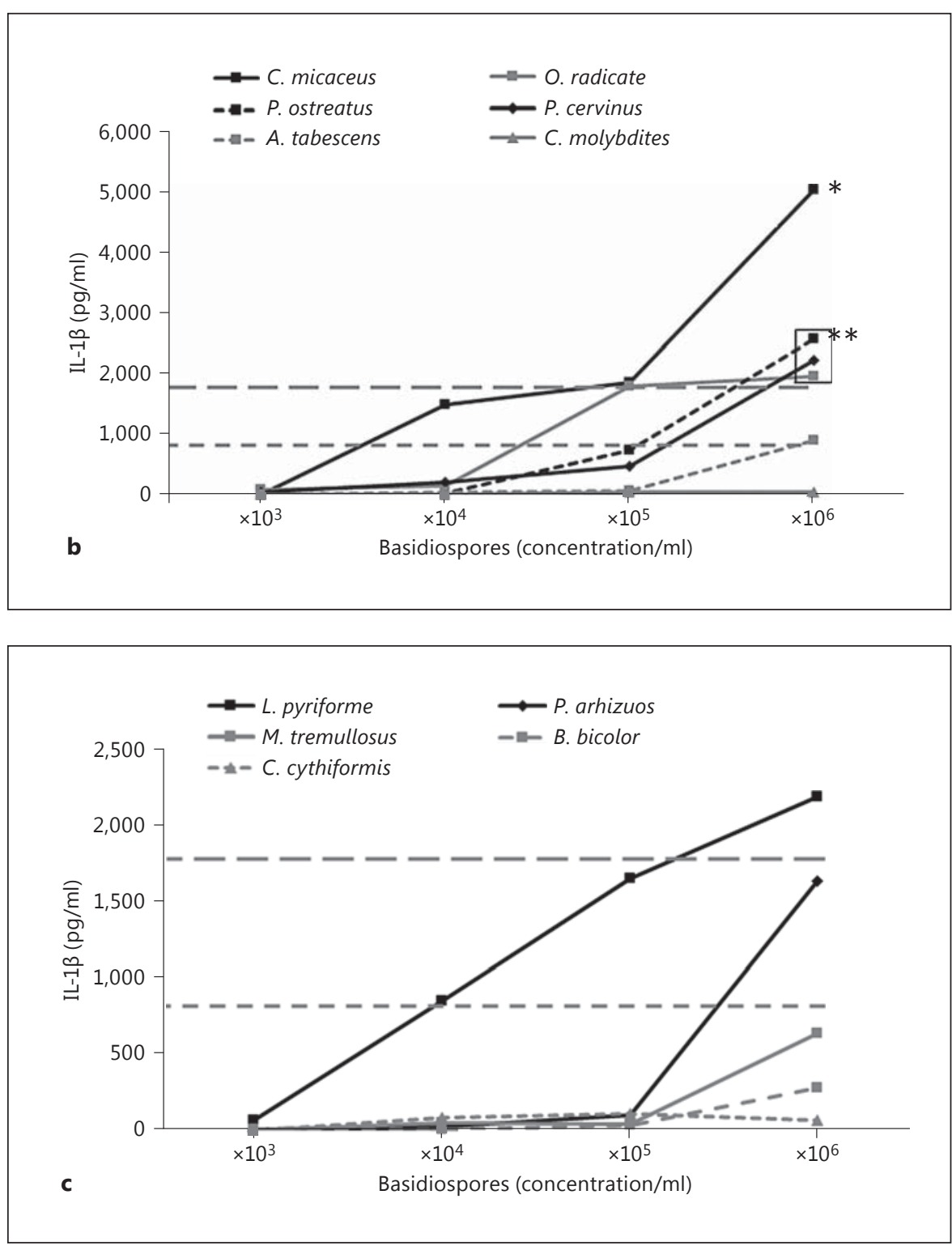
Fig. 3. Higher variability in IL- $1 \beta$-inducing potency at higher concentrations of basidiospores. Levene's test of equal variances was performed to determine the concentration of basidiospores that, overall, induced the highest variability in the IL-1 $\beta$ inducing potency after stimulation in the human whole blood. $* \mathrm{p}<0.05$ vs. variance of $10^{3}, 10^{4}, 10^{5}$ basidiospores $/ \mathrm{ml}$.

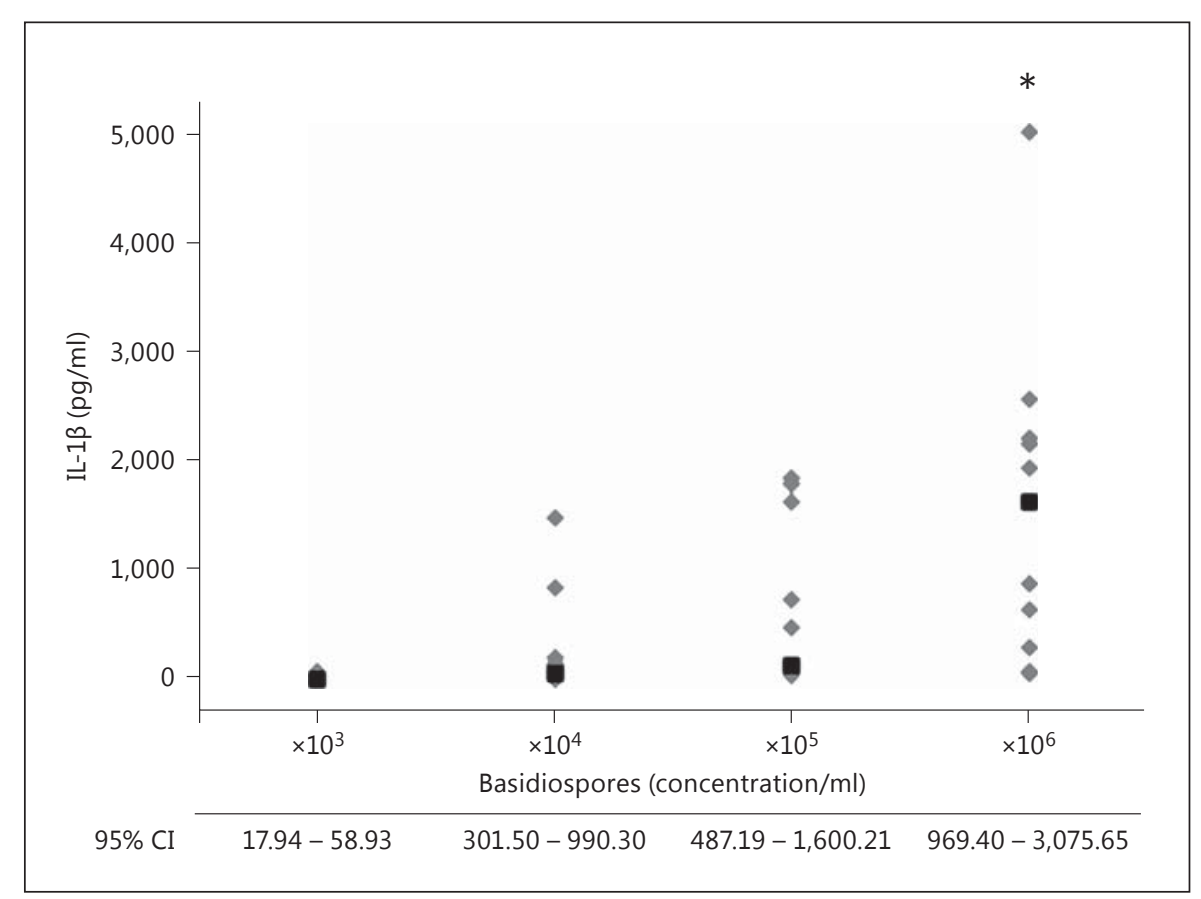

centration-dependent IL- $1 \beta$-inducing potency. Basidiospores from gilled mushrooms (fig. 2b), similar to LPS, stimulated a concentration-dependent IL- $1 \beta$-inducing potency, with $C$. micaceus inducing the highest response. At $10^{6}$ basidiospores $/ \mathrm{ml}$, C. micaceus was the only species that induced a response significantly higher than that induced by 0.5 and 0.25 nanograms of endotoxin $/ \mathrm{ml}$. IL- $1 \beta$ inducing potencies of $P$. ostreatus, $O$. radicata, and $P$. cervinus were significantly higher than that of $0.25 \mathrm{ng} / \mathrm{ml}$ of LPS. Among the nongilled basidiomycetes (fig. 2c), only L. pyriforme induced a marked concentration-dependent IL-1 $\beta$ response. None of the nongilled basidiomycetes induced a response significantly higher than 0.5 and 0.25 $\mathrm{ng} / \mathrm{ml}$ of LPS.

To test for variability in the IL- $1 \beta$-inducing potency between different concentrations of basidiospores, Levene's test of equal variance was performed. As concentration increased, the variability in IL- $1 \beta$-inducing potency between basidiospores was more evident. The variability of the IL- $1 \beta$-inducing potency of the basidiospores tested was significantly higher $(\mathrm{p}, 0.002)$ at $10^{6}$ basidiospores $/ \mathrm{ml}$ (fig. 3). Similar to what is shown in figure $2 \mathrm{~b}, \mathrm{c}$, at $10^{3} \mathrm{ba}-$ sidiospores $/ \mathrm{ml}$ the IL- $1 \beta$-inducing potency of the basidiospores tested was barely noticeable. Altogether, these data suggest that allergenic basidiospores have a concentration-dependent IL-1 $\beta$-inducing potency, and that this potency can be different at higher concentrations of basidiospores.

IL-1 $\beta$-Inducing Potency of Allergenic Basidiospores

\section{Morphological Features of Basidiospores Did Not} Modulate IL-1ß-Inducing Potency

To evaluate the role of morphological features of basidiospores in their IL- $1 \beta$-inducing potency, surface area (pixels ${ }^{2}$ ), circularity (R), and pigmentation (as a measure of color integrated density) of basidiospores were determined with image analysis (table 1). The Spearman rank correlation coefficient was calculated between the morphological features and the IL- $1 \beta$-inducing potency of the basidiospores at $10^{6} / \mathrm{ml}$ (the concentration of spores at which the highest variability in IL-1 $\beta$-inducing potency was detected for the species tested). The morphological measurements varied widely and no correlation was found between morphological features and the IL- $1 \beta$ inducing potency. This finding suggests that nonmorphological properties of basidiospores modulate their IL$1 \beta$-inducing potency in the cryopreserved human whole blood.

\section{Discussion}

In this study, we examined species of basidiomycete fungi with documented allergenic potential and determined their respective proinflammatory potency of their spores in a cryopreserved human whole blood system. Our data suggest that the cryopreserved human whole blood provides a useful tool to determine the proinflam-

Int Arch Allergy Immunol 2014;163:154-162 
Table 2. Spearman's rank correlation coefficient between IL-1 $\beta$ inducing potency of $10^{6}$ basidiospores $/ \mathrm{ml}$ and morphological measurements

\begin{tabular}{llll}
\hline & Surface area & Circularity & $\begin{array}{l}\text { Integrated } \\
\text { density }\end{array}$ \\
\hline $\mathrm{R}$ & 0.405 & 0.378 & 0.291 \\
$\mathrm{p}$ value & 0.216 & 0.252 & 0.521 \\
\hline
\end{tabular}

matory potency of spores of higher fungi, such as basidiomycetes. More importantly, the study further adds to the potential health effects of basidiospores.

Stimulation of human whole blood with basidiospores induced a defined concentration-dependent proinflammatory potency (fig. 2), mainly in gilled basidiomycetes. This is similar to previous studies in which other non-LPS stimuli, such as peptidoglycan from Gram-positive bacteria, polyinosinic-polycytidylic acid (analog of doublestranded RNA), zymosan (component of the cell wall from fungal spores), and whole spores from mitosporic fungi (e.g. Cladosporium spp., Alternaria spp., and Penicillium spp.) induced concentration-dependent responses of proinflammatory cytokines in human whole blood [27-29]. Similar to the findings of Daneshian [28], polymyxin B sulfate did not affect the IL- $1 \beta$-inducing poten$\mathrm{cy}$, at least in the gilled mushrooms (fig. 2b). It remains to be determined if this polycationic compound affects the proinflammatory potency of spores from nongilled basidiomycetes at lower concentrations $\left(<10^{6}\right.$ basidiospores $/ \mathrm{ml}$; fig. 2c). Despite this, our data suggest that allergenic basidiospores do possess proinflammatory potential. In addition, our study provides evidence that the cryopreserved human whole blood system may be used in conjunction with compounds that can inhibit the action of other proinflammatory microbial components to study the proinflammatory potential of spores from allergenic basidiomycetes.

Basidiomycetes are the most morphologically diverse fungi, and their spores are often morphologically distinct within a particular genus [30]. In addition, many species have small diameters $(<2.5 \mu \mathrm{m})$, which may allow them to reach lower anatomical sites (e.g. alveoli) of the respiratory tract, which is important in inducing asthmatic episodes [31,32]. Size is an important parameter for particle uptake by resident antigen-presenting cells (e.g. dendritic cells and macrophages) and the initiation of immune responses in the lower respiratory tract [33]. For these reasons, we proceeded to examine whether mor- phological features, such as the surface area of the spore, shape (as a measure of circularity), and pigmentation (as a measure of color-integrated density), contribute to the IL-1 $\beta$-inducing potency. These features often vary between genera and sometimes between species. Interestingly, we did not find any correlation between morphological features and the IL- $1 \beta$-inducing potency of the basidiospores (table 2). The presence and concentration of different cell wall chemical components such as $\beta$-glucan, mannans, chitin (long-chain polymer of acetylglucosamine), and melanin on the surface of fungal spores may explain the variability in basidiospores, as it has been shown using spores of mitosporic micromycetes that these compounds play a role in their interaction and activation of innate immune cells [14, 34-36]. Furthermore, $\beta$-glucans with different glycosidic linkages and molecular weights differ in their proinflammatory potency [37]. Therefore, properties of basidiospores beyond morphology may have active roles in the variable proinflammatory potency observed in our study. Nonetheless, the human whole blood system in our study was able to determine the variable proinflammatory responses between spores of basidiomycete species, which opens the opportunity to further explore the role of structural chemical components of basidiospores in their proinflammatory potency.

Limitations of this study include the number of basidiomycete species tested. Because of the difficulty to cultivate them in laboratory conditions, studies with basidiomycetes often rely on collecting fruiting bodies in the field. The limited availability of enough specimens harvested from the field is commonly one of the main reasons studies with basidiomycetes rarely include beyond 10 species [38]. Another limitation is evaluating the proinflammatory potency based solely on IL- $1 \beta$. We focused our study on this biomarker based on previous validation studies that have shown its reliability as a good proinflammatory end point in the human whole blood system $[23,24]$. We intend to further examine the proinflammatory potency of basidiomycetes based on additional biomarkers, such as other cytokines and chemokines that participate in innate immune responses.

Spores from basidiomycete fungi have been shown to significantly contribute to the fungal ecology in the atmosphere of rural and suburban environments $[1,2,6]$. Aerobiological studies have shown that concentrations of basidiospores may reach, depending on the environmental factors, yearly concentrations $>100,000$ spores $/ \mathrm{m}^{3}$, and genetic analyses of airborne samples have shown species of gilled fungi to be the most predominant among spores 
of basidiomycetes $[2,38]$. Similarly, clinical studies have elucidated the potential of airborne basidiospores to exacerbate episodes of respiratory allergies, such as allergic asthma and rhinitis, among susceptible individuals. All fungal species from the basidiomycete group previously studied demonstrated to have allergenic potential [31,32, 39-42]. However, insights into the priming or proinflammatory properties of basidiospores, as it has been shown with other allergens [43-45], is lacking. In these studies with other allergens (e.g. mite and cat allergens), priming of the innate immune system through proinflammatory cascades adds to the allergenicity of the allergens. These were strong motivating factors for evaluating the proinflammatory potential of allergenic basidiospores in this study. The differences in proinflammatory potency between gilled and nongilled mushrooms may suggest that the allergenic potential of this group of fungi also relies on their proinflammatory potency, and may pose additional respiratory health risks to susceptible individuals. Additional studies are needed to provide more evidence regarding the interface between the proinflammatory and allergenic potencies of spores from basidiomycetes and their role in potential human health effects.

In summary, our data demonstrate the utility of the cryopreserved human whole blood system as a tool to study the proinflammatory potency of allergenic basidiospores. It also provides additional evidence of the potential human health effects, beyond allergies, which basidiospores could have once they interact with the innate immune system. Additional studies are warranted to further characterize the innate immune-activating properties of fungal spores of basidiomycetes in a human-based system.

\section{Acknowledgments}

This research was supported by the National Institute of Environmental Health Sciences (T32 ES O7141-28, PO1 ES 018176, P50 ES 015903 and UO1 FD004230), the United States Environmental Protection Agency (RD8345101) and the Ethical Consumer Research Association (2012 Lush Young Researcher Award). Dr. Thomas Hartung is holding patents for the whole blood pyrogen test used in this study. We are grateful to Dr. Kellog Schwab's laboratory for allowing the use of their microplate reader. We also thank the phlebotomist Christine Torrey and the volunteers of the Johns Hopkins School of Public Health staff for contributing to the blood sampling.

\section{Disclosure Statement}

The authors have no conflict of interest to disclose.

\section{References}

1 Quintero E, Rivera-Mariani F, Bolaños-Rosero B: Analysis of environmental factors and their effects on fungal spores in the atmosphere of a tropical urban area (San Juan, Puerto Rico). Aerobiologia 2010;26:113-124.

$\checkmark 2$ Frohlich-Nowoisky J, Pickersgill DA, Despres VR, Poschl U: High diversity of fungi in air particulate matter. Proc Natl Acad Sci USA 2009;106:12814-12819.

-3 Oliveira M, Ribeiro H, Delgado JL, Abreu I: Seasonal and intradiurnal variation of allergenic fungal spores in urban and rural areas of the North of Portugal. Aerobiologia 2009; 25:85-98.

-4 Hurtado I, Leal Quevedo FJ, Rodriguez Ciodaro A, Garcia Gomez E, Alson-Haran J: A one year survey of airborne pollen and spores in the neotropical city of Bogota (Colombia). Allergol Immunopathol (Madr) 1989;17:95104.

5 Hasnain S, Fatima K, Al-Frayh A, Al-Sedairy S: One-year pollen and spore calendars of Saudi Arabia Al-Khobar, Abha and Hofuf. Aerobiologia 2005;21:241-247.

IL-1 $\beta$-Inducing Potency of Allergenic Basidiospores
6 Oliveira M, Ribeiro H, Delgado L, Fonseca J, Castel-Branco MG, Abreu I: Outdoor allergenic fungal spores: comparison between an urban and a rural area in northern Portugal. J Investig Allergol Clin Immunol 2010;20:117128.

7 Elbert W, Taylor PE, Andreae MO, Pöschl U: Contribution of fungi to primary biogenic aerosols in the atmosphere: wet and dry discharged spores, carbohydrates, and inorganic ions. Atmos Chem Phys 2007;7:4569-4588.

-8 Bauer H, Schueller E, Weinke G, Berger A, Hitzenberger R, Marr IL, Puxbaum H: Significant contributions of fungal spores to the organic carbon and to the aerosol mass balance of the urban atmospheric aerosol. Atmos Environ 2008;42:5542-5549.

-9 Santilli J Jr, Rockwell WJ, Collins RP: The significance of the spores of the basidiomycetes (mushrooms and their allies) in bronchial asthma and allergic rhinitis. Ann Allergy 1985;55:469-471.

10 Rivera-Mariani FE, Nazario-Jimenez S, Lopez-Malpica F, Bolanos-Rosero B: Sensitization to airborne ascospores, basidiospores, and fungal fragments in allergic rhinitis and asthmatic subjects in San Juan, Puerto Rico. Int Arch Allergy Immunol 201 1;155:322-334.
11 Green BJ, Sercombe JK, Tovey ER: Fungal fragments and undocumented conidia function as new aeroallergen sources. J Allergy Clin Immunol 2005;115:1043-1048.

12 Dales RE, Cakmak S, Burnett RT, Judek S, Coates F, Brook JR: Influence of ambient fungal spores on emergency visits for asthma to a regional children's hospital. Am J Respir Crit Care Med 2000;162:2087-2090.

13 Reponen T, Grinshpun SA, Conwell KL, Wiest J, Anderson M: Aerodynamic versus physical size of spores: measurement and implication for respiratory deposition. Grana 2001;40:119-125.

14 Netea MG, Ferwerda G, van der Graaf CAA, Van der Meer JWM, Kullberg BJ: Recognition of fungal pathogens by toll-like receptors. Curr Pharm Des 2006;12:4195-4201.

15 Faro-Trindade I, Willment JA, Kerrigan AM, Redelinghuys P, Hadebe S, Reid DM, Srinivasan N, Wainwright H, Lang DM, Steele C, Brown GD: Characterisation of innate fungal recognition in the lung. PloS One 2012; $7: \mathrm{e} 35675$

16 Kauffman HF: Innate immune responses to environmental allergens. Clin Rev Allergy Immunol 2006;30:129-140. 
17 Kindinger I, Daneshian M, Baur H, Gabrio T, Hofmann A, Fennrich S, von Aulock S, Hartung T: A new method to measure air-borne pyrogens based on human whole blood cytokine response. J Immunol Methods 2005;298: 143-153.

18 Hartung T, Wendel A: Detection of pyrogens using human whole blood. ALTEX 1995;12: 70-75.

19 Langezaal I, Hoffmann S, Hartung T, Coecke S: Evaluation and prevalidation of an immunotoxicity test based on human whole-blood cytokine release. Altern Lab Anim 2002;30: 581-595.

20 Hartung T, Fennrich S, Fischer M, MontagLessing T, Wendel A: Development and evaluation of a pyrogen test based on human whole blood. ALTEX 1998;15:9-10.

-21 Hasiwa M, Kullmann K, von Aulock S, Klein C, Hartung T: An in vitro pyrogen safety test for immune-stimulating components on surfaces. Biomaterials 2007;28:1367-1375.

22 Mattsson E, Hartung T, Morath S, Egesten A: Highly purified lipoteichoic acid from Staphylococcus aureus induces procoagulant activity and tissue factor expression in human monocytes but is a weak inducer in whole blood: comparison with peptidoglycan. Infect Immun 2004;72:4322-4326.

23 Hoffmann S, Peterbauer A, Schindler S, Fennrich S, Poole S, Mistry Y, Montag-Lessing T, Spreitzer I, Loschner B, van Aalderen M, Bos R, Gommer M, Nibbeling R, Werner-Felmayer G, Loitzl P, Jungi T, Brcic M, Brugger P, Frey E, Bowe G, Casado J, Coecke S, de Lange J, Mogster B, Naess LM, Aaberge IS, Wendel A, Hartung T: International validation of novel pyrogen tests based on human monocytoid cells. J Immunol Methods 2005;298: 161-173.

24 Schindler S, Spreitzer I, Loschner B, Hoffmann S, Hennes K, Halder M, Brugger P, Frey E, Hartung T, Montag T: International validation of pyrogen tests based on cryopreserved human primary blood cells. J Immunol Methods 2006;316:42-51.
25 Schindler S, Asmus S, von Aulock S, Wendel A, Hartung T, Fennrich S: Cryopreservation of human whole blood for pyrogenicity testing. J Immunol Methods 2004;294:89-100.

26 Burger W, Burge M: Digital Image Processing: An Algorithmic Introduction Using Java, ed 1. New York, Springer, 2008.

27 Nakagawa Y, Maeda H, Murai T: Evaluation of the in vitro pyrogen test system based on proinflammatory cytokine release from human monocytes: comparison with a human whole blood culture test system and with the rabbit pyrogen test. Clin Diagn Lab Immunol 2002;9:588-597.

28 Daneshian M: Detection and Characterization of the Immunostimulatory Properties of Airborne Pyrogens: Biochemical Pharmacology; $\mathrm{PhD}$ thesis, University of Konstanz, Konstanz, 2006, p 123.

29 Hasiwa N, Daneshian M, Bruegger P, Fennrich S, Hochadel A, Hoffmann S, RiveraMariani FE, Rockel C, Schindler S, Spreitzer I, Stoppelkamp S, Vysyaraju K, Hartung T: Evidence for the detection of non-endotoxin pyrogens by the whole blood monocyte activation test. ALTEX 2013;30:169-208.

30 Alexopoulos CJ, Mims CW, Blackwell M: Introductory Mycology, ed 4. New York, Wiley, 1996.

31 Horner W, Helbling A, Salvaggio JE: Fungal allergens. Clin MIcrobiol Rev 1995;8:161179.

32 Horner WE, Helbling A, Lehrer SB: Basidiomycete allergens. Allergy 1998;53:1114-1121.

33 Blank F, Stumbles PA, Seydoux E, Holt PG, Fink A, Rothen-Rutishauser B, Strickland $\mathrm{DH}$, von Garnier C: Size-dependent uptake of particles by pulmonary antigen-presenting cell populations and trafficking to regional lymph nodes. Am J Respir Cell Mol Biol 2013; 49:67-77.

34 Levitz SM: Innate recognition of fungal cell walls. PLoS Pathog 2010;6:e1000758.

35 Figueiredo RT, Carneiro LA, Bozza MT: Fungal surface and innate immune recognition of filamentous fungi. Front Microbiol 2011;2: 248.

- 36 Mintz-Cole RA, Gibson AM, Bass SA, Budelsky AL, Reponen T, Hershey GK: Dectin-1 and IL-17a suppress murine asthma induced by Aspergillus versicolor but not Cladosporium cladosporioides due to differences in beta-glucan surface exposure. J Immunol 2012;189:3609-3617.
- 37 Noss I, Doekes G, Thorne PS, Heederik DJ, Wouters IM: Comparison of the potency of a variety of $\beta$-glucans to induce cytokine production in human whole blood. Innate Immun 2013;19:10-19.

38 Rivera-Mariani F, Bolaños-Rosero B: Allergenicity of airborne basidiospores and ascospores: need for further studies. Aerobiologia 2012;28:83-97.

-39 Simon-Nobbe B, Denk U, Poll V, Rid R, Breitenbach M: The spectrum of fungal allergy. Int Arch Allergy Immunol 2008;145:58-86.

-40 Lehrer SB, Hughes JM, Altman LC, Bousquet J, Davies RJ, Gell L, Li J, Lopez M, Malling HJ, Mathison DA, et al: Prevalence of basidiomycete allergy in the USA and Europe and its relationship to allergic respiratory symptoms. Allergy 1994;49:460-465.

-41 Sprenger JD, Altman LC, O’Neil CE, Ayars GH, Butcher BT, Lehrer SB: Prevalence of basidiospore allergy in the pacific northwest. J Allergy Clin Immunol 1988;82:1076-1080.

- 42 Helbling A, Gayer F, Pichler WJ, Brander KA Mushroom (basidiomycete) allergy: diagnosis established by skin test and nasal challenge. J Allergy Clin Immunol 1998;102:853858.

43 Herre J, Grönlund H, Brooks H, Hopkins L, Waggoner L, Murton B, Gangloff M, Opaleye O, Chilvers ER, Fitzgerald K, Gay N, Monie T, Bryant C: Allergens as immunomodulatory proteins: the cat dander protein Fel d 1 enhances TLR activation by lipid ligands. J Immunol 2013;191:1529-1535.

44 Trompette A, Divanovic S, Visintin A, Blanchard C, Hegde RS, Madan R, Thorne PS, Wills-Karp M, Gioannini TL, Weiss JP, Karp CL: Allergenicity resulting from functional mimicry of a Toll-like receptor complex protein. Nature 2009;457:585-588.

45 Chiou Y-L, Lin C-Y: Der p2 activates airway smooth muscle cells in a TLR2/MyD88-dependent manner to induce an inflammatory response. J Cell Physiol 2009;220:311-318. 